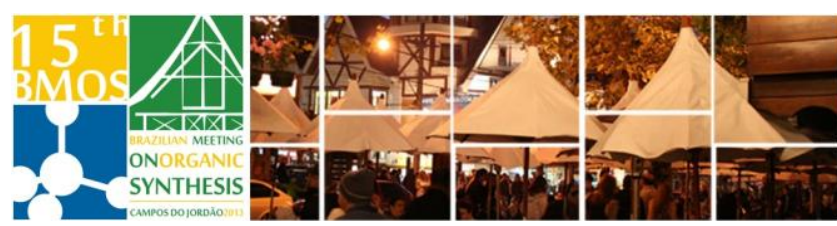

\title{
Semi-synthes is of Purpurinimides: The search for more effective PDT agents
}

\author{
Marciana P. Uliana, ${ }^{1,2}$ Timothy J. Brocksom, ${ }^{1}$ Kleber T. de Oliveira, ${ }^{1}$ Vanderlei S. \\ Bagnato $^{2}$ and Cristina Kurachi. ${ }^{\star 2}$ \\ 1- Universidade Federal de São Carlos - UFSCar, Departamento de Química,13565-905, São Carlos, SP, \\ Brazil. \\ ${ }^{2}$ Instituto de Física de São Carlos-IFSQ-USP, 13566-590, São Carlos, SP, Brazil. \\ email: *cristina@ifsc.usp.br
}

Keywords: Photosensitizers, Photodynamic therapy, Semi-synthesis.

\section{INTRODUCTION}

Photodynamic therapy (PDT) is an emergent technique for treatment of diseases caused by resistant microorganisms, skin cancer and other diseases. ${ }^{1}$ Although the use of various photosensitizers (PS) in PDT has been reported, there are still many challenges to be overcome. Strategies for the synthesis of new photosensitizers, based on chlorophyll moieties, are being developed in our research group. The aim is to synthesize new molecules with absorption in the near IR that will be more adequate for PDT treatments.

\section{RESULTS AND DISCUSSION}

Two different approaches were used to prepare the purpurin 2: the one-pot extraction/transformation from Spirulina maxima to $\mathbf{1}$, and subsequent reaction with $\mathrm{O}_{2} / \mathrm{NaOH} /$ acetone ( $a$ and $b$ ), or by the direct reaction between the alga in $\mathrm{O}_{2} / \mathrm{NaOH} /$ acetone (c) (Scheme 1). The direct route (c) from Spirulina maxima is easier to execute than the two-step procedure, and the overall yields are similar.

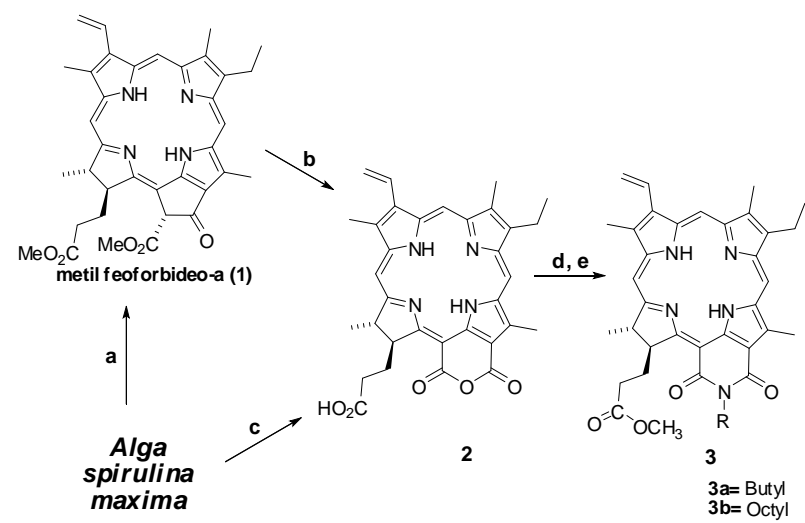

Conditions: a) $\mathrm{MeOH}, \mathrm{H}_{2} \mathrm{SO}_{4}, 48 \mathrm{~h}, 0.8 \%$ b) i) $\mathrm{O}_{2}, \mathrm{NaOH}$, acetone, 3h, ii) $\mathrm{H}^{+} 60 \%$ c) i) $\mathrm{O}_{2}, \mathrm{NaOH}$, acetone, ii) $\mathrm{H}^{+}, 0.4 \%$;d) $\mathrm{CH}_{2} \mathrm{~N}_{2}, \mathrm{CH}_{2} \mathrm{Cl}_{2}, 10$ min, $88 \%$ e) i) amine, $\mathrm{CH}_{2} \mathrm{Cl}_{2}, 2 \mathrm{~h}$, ii) $\mathrm{CH}_{2} \mathrm{~N}_{2}$, $\mathrm{CH}_{2} \mathrm{Cl}_{2}$, iii) $\mathrm{KOH}, \mathrm{MeOH}, 3 \mathrm{a}=75 \%, \mathbf{3 b}=54 \%$.
Purpurin (2) was then reacted with two aliphatic primary amines ( $N$-butyl and $N$-octyl) in order to prepare the two different hydrophobic derivatives $\mathbf{3 a}$ and $\mathbf{3 b}$, respectively. We are now preparing some glycol-derivatives using the synthetic sugars $\mathbf{8 a}$ and 8b (Scheme 2).

All the purpurinimides are being tested against different microorganisms, in order to evaluate the differences between hydrophobic and hydrophilic structures in PDT treatments.

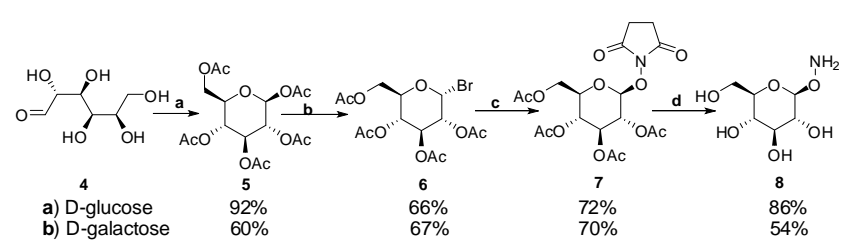

Conditions: a) $\mathrm{Ac}_{2} \mathrm{O}$; b) $\mathrm{HBr} / \mathrm{HOAc}, \mathrm{Ac}_{2} \mathrm{O} ; \quad$ c) $\mathrm{N}$ hydroxy succinimide, TBAHS, $\mathrm{CH}_{2} \mathrm{Cl}_{2}$; d) $\mathrm{NH}_{2} \mathrm{NH}_{2}, \mathrm{H}_{2} \mathrm{O}, \mathrm{MeOH}$.

\section{Scheme 2}

\section{CONCLUSION}

The purpurinimides with aliphatic substituents were successfully obtained, and some glycol derivatives are under study. All the purpurinimides are being tested against microorganisms using the PDT technique.

\section{ACKNOWLEDGEMENTS}

The authors thank FAPESP (process numbers: 2011/19720-8, 2011/13993-2, 2013/06532-4 and CEPOF 98/14270-8), CNPq and CAPES for financial support and fellowships.

\section{REFERENCES}

${ }^{1}$ Ferraz, R, C, M, C.; Fontana, C. R.; Ribeiro, A. P.; Trindade, F. Z.; Bartoloni, F. H.; Baader, J. W.; Lins, E. C.; Bagnato, V. S.; Kurachi, C. J. Photochem Photobiol B, 2011, 103, 87-92.

${ }^{2}$ Garland, M, J.; Cassidy, C. M. Woolf son, D.; Donnely, R. F.; Future Med. Chem. 2009, 1, 667-691.

Scheme 1 